\title{
The Relationship between Scabies and Stroke: A Population-Based Nationwide Study
}

\author{
Meng-Huan $\mathrm{Wu}^{1}$, Chien-Yu Li ${ }^{2}$, Huichin Pan ${ }^{3,4, *}$ and $\mathrm{Yu}-\mathrm{Chieh}$ Lin ${ }^{5,6, *}$ \\ 1 Department of Emergency Medicine, Chang Guan Memorial Hospital, Kaohsiung 83301, Taiwan; \\ m7169@cgmh.org.tw \\ 2 Department of Neurosurgery, Asia University Hospital, Department of Occupational Therapy, \\ Asia University, Taichung 41354, Taiwan; sbrain.lee@gmail.com \\ 3 Department of Biomedical Sciences, Chung Shan Medical University, Taichung 40201, Taiwan \\ 4 Department of Medical Research, Chung Shan Medical University Hospital, Taichung 40201, Taiwan \\ 5 Department of Pathology and Laboratory Medicine, Taoyuan Armed Forces General Hospital, \\ Taoyuan 32551, Taiwan \\ 6 Department of Pathology and Graduate Institute of Pathology and Parasitology, Tri-Service General \\ Hospital, National Defense Medical Center, Taipei 11490, Taiwan \\ * Correspondence: hp29@csmu.edu.tw (H.P.); medicalwolf1981@gmail.com (Y.-C.L.)
}

Received: 23 July 2019; Accepted: 12 September 2019; Published: 19 September 2019

\begin{abstract}
Background: Scabies is a commonly occurring infectious skin infestation that substantially impacts the quality of life, while stroke, which consists of a neurological deficit resulting from a lack of blood flow to the brain, carries sizable economic costs. The pathophysiologic mechanisms underlying both diseases involve inflammatory processes that are mediated by the immune system; however, no prior research has been conducted to explore the relationship between the two conditions. Methods: This population-based nationwide study utilized data from the National Health Insurance Research Database (NHIRD) of Taiwan for a total of 6628 scabies patients, who comprised a scabies group, and a randomly selected cohort of 26,509 matching patients, who served as a control group. More specifically, the medical records for the patients in both groups were checked for seven years to identify any new cases of stroke within that seven-year follow-up period. The hazard ratio (HR) of stroke for the follow-up period was then calculated using Cox proportional hazards regressions, while comorbidities and demographic characteristics were likewise analyzed. Results: During the follow-up period, 2892 patients, or $8.7 \%$, of the overall total of 33,137 patients included in the study were newly diagnosed with a stroke. Of those newly diagnosed stroke patients, 833 were from the scabies group, and 2059 were from the control group, accounting for $12.6 \%$ and $7.8 \%$, respectively, of the individuals in each group. With a crude hazard ratio of 1.67 , the patients in the scabies group had a significantly higher risk of subsequent stroke than those in the control group, although the adjusted hazard ratio (aHR) for the scabies patients, which was determined by adjusting for covariates, was only 1.32 (95\% confidence interval (CI): 1.21-1.43). Conclusions: The results of the study indicated an elevated risk of stroke among scabies patients, an association that might be contributed to by immunopathological factors. This information could serve as a reminder to clinicians to remain alert to any indications of neurological impairment in patients previously infected with scabies.
\end{abstract}

Keywords: scabies; stroke; National Health Insurance Research Database

\section{Introduction}

Scabies is a highly contagious and commonly occurring ectoparasitic skin disease resulting from infection by the mite Sarcoptes scabiei [1-3]. The most common symptom is severe itchiness caused by intense pruritic skin lesions, with patient quality of life frequently being severely impacted as 
a result. The symptom of itchiness typically causes scratching, and the resulting scratches often lead, in turn, to secondary bacterial infections; also, an elevated danger of chronic kidney disease after scabies infection has been reported [4,5]. Immune responses and inflammatory reactions mediate the underlying pathophysiological mechanisms of scabies infection [6].

Stroke, which is also termed cerebrovascular accident (CVA), constitutes a leading source of disability around the globe, accounting for over $4 \%$ of healthcare costs in developed nations and $2 \%$ to $4 \%$ of all healthcare costs around the world [7]. A stroke subsequently leads to major disability in one-third to half of all cases, with such patients becoming heavily dependent on others for daily necessities [8]. Neurological impairments, such as dysphagia, aphasia, altered consciousness, sensory impairment, and motor weakness, constitute the most commonly occurring manifestations of stroke, while early detection of stroke risk can be helpful in allowing potential victims and their physicians to take preventative measures, with common risk factors, including obesity, diabetes, hypertension, and hyperlipidemia $[9,10]$. Inflammation and chronic infection have also been reported by some studies to be potential risk factors [11,12].

In spite of a potential association, no previous studies have been conducted to elucidate the relationship between stroke and scabies. The present study, a 14-year population-based study in Taiwan, was thus conducted to investigate that relationship.

\section{Materials and Methods}

\subsection{Database}

Taiwan's National Health Insurance Research Database (NHIRD) was the source of the data used in this study. The National Health Insurance (NHI) program, which was initiated in 1995 and covered $99.9 \%$ of Taiwan's population of 23 million as of 2013, is the national medical insurance and healthcare system of Taiwan, and the NHIRD includes the data (such as demographic data, medical records, prescription records, and medical procedures) of those who seek medical care through the NHI program [13]. More specifically, this study utilized data from the Longitudinal Health Insurance Database 2000 (LHID2000), which is a sub-database of the NHIRD and is comprised of one million randomly selected people included in the NHIRD as of 2000. This study was approved by the Institutional Review Board of the Tri-Service General Hospital (approval No: B-105-06, 04/12/2016 Taipei, Taiwan).

\subsection{Study Population}

The study population was selected from LHID2000 data covering the period from January 2000 through December 2013, with all those patients newly diagnosed with scabies between January 2001 and December 2006 comprising the scabies group (Figure 1).

The clinical diagnoses included in the NHIRD are determined by licensed physicians and are made based on the International Classification of Diseases, 9th revision, Clinical Modification (ICD-9-CM) system, with 133.0 being the ICD-9-CM code for scabies infection [14]. The exclusion criteria for the study consisted of the following: (1) any diagnosis of scabies made prior to January 1, 2001 (1420), (2) missing medical records $(n=115)$, (3) an age of 0 to 19 years old at the time of scabies diagnosis $(n=2492)$, and (4) any prior history of scabies or stroke $(n=1302)$. Ultimately, 6628 scabies patients were enrolled in the scabies group, while a non-scabies control group totaling 26,509 subjects was filled by patients randomly matched to the scabies group on the basis of age (20-29 years, 30-39 years, $40-49$ years, $50-59$ years, $60-69$ years, and $\geq 70$ years), gender, index year of scabies diagnosis, insured region, and urbanization at a ratio of 1:4.

Starting with his or her index date, each subject was tracked for a seven-year period to identify those who were diagnosed with stroke (ICD-9-CM: 430-438) within those seven years, with all medical diagnoses, medical procedures, and prescriptions of those subjects during the follow-up period also being identified and recorded. Each diagnosis of stroke was considered valid if made by a psychiatrist 
in conjunction with at least one admission to hospital or if there were at least three consistent diagnoses made in outpatient department visits, while each scabies diagnosis was determined by a licensed physician according to a detailed physical examination and history taking for the patient in question. More specifically, the clinical diagnoses of scabies required findings typical of scabies, such as inflammatory pruritic papules, burrows, or nodules; generalized itching, sparing the face; and severe pruritus, especially at night [1].

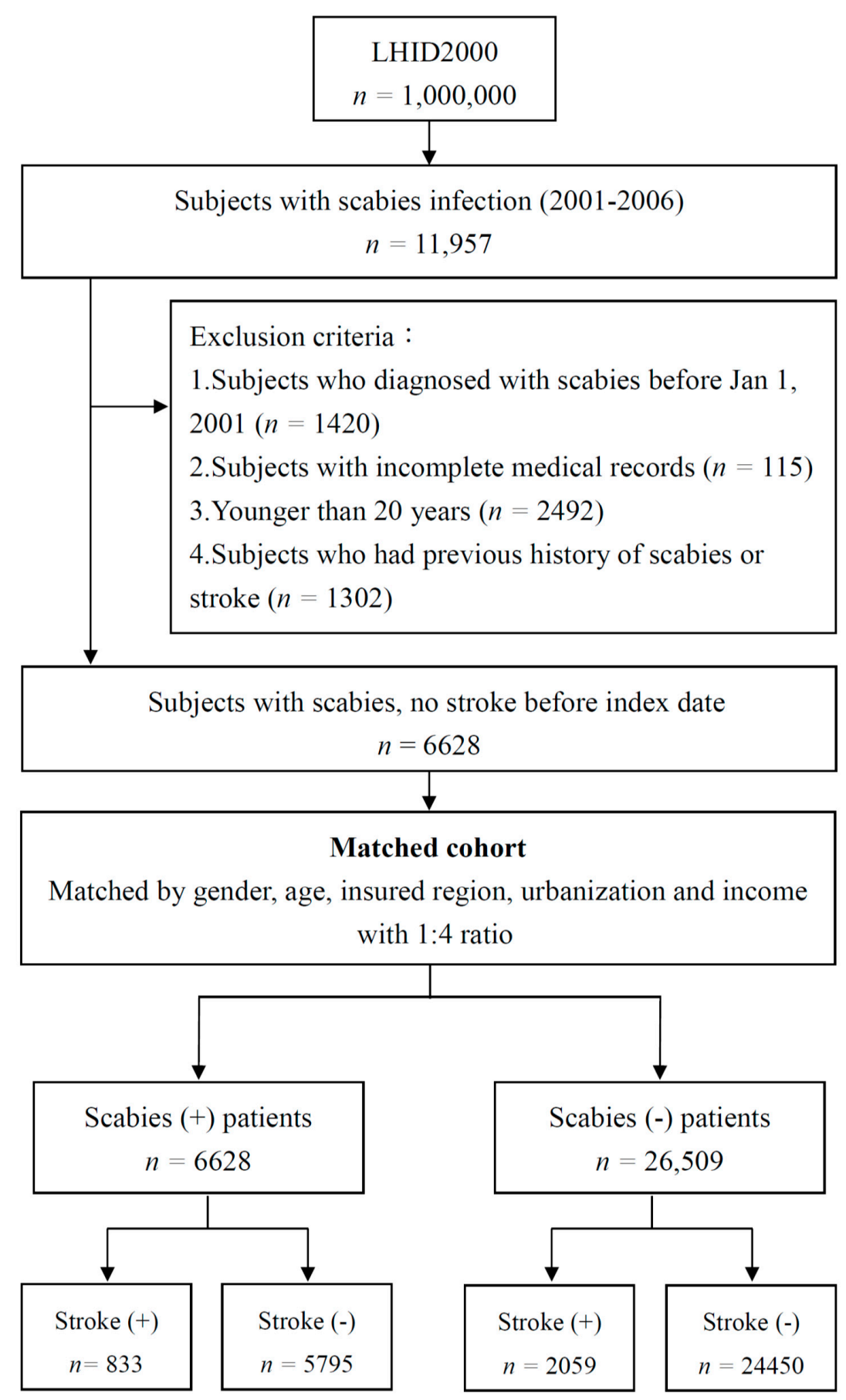

Figure 1. Flowchart of recruitment of subjects from the 1-million random sample of the National Health Insurance Research Database (NHIRD) from 2000 to 2006 in Taiwan. The exclusion criteria of the study was including: (1) Patients who were diagnosed with scabies before 1 January $2001(n=1420)$; (2) Patients with missing medical records $(n=115)$; (3) patients <19 years old $(n=2492)$; (4) patients with history of scabies or stroke $(n=1302)$. 


\subsection{Covariates}

The following comorbidities were selected as covariates for this study: coronary heart disease (ICD-9-CM: 410-414), congestive heart failure (ICD-9-CM: 428), chronic kidney disease (ICD-9-CM: 585,586,588), hypertension (ICD-9-CM: 401-405), hyperlipidemia (ICD-9-CM: 272.4), diabetes mellitus (ICD-9-CM: 250), and atrial fibrillation (ICD-9-CM: 427.31). Patients were categorized by age into six groups determined by ten-year intervals: 20 to 29 years, 30 to 39 years, 40 to 49 years, 50 to 59 years, 60 to 69 years, and 70 years and older. Patients were also categorized into 4 categories based on their monthly incomes in New Taiwan Dollars (NTD): less than NTD 20,000, NTD 20,000 to NTD 39,999, NTD 40,000 to NTD 59,999, and more than NTD 60,000. Patients were likewise divided into 7 categories based on the level of urbanization of their residences [15]. Finally, the patients were categorized into four groups according to the geographic area of Taiwan in which they resided: the northern region, central region, southern region, or "other" region (eastern and outlying islands).

\subsection{Statistical Analysis}

Version 19.0 of the SPSS software package (SPSS Inc., Chicago, IL, USA) was utilized for the statistical analysis, while Microsoft ${ }^{\circledR}$ SQL Server ${ }^{\circledR} 2008$ software (Microsoft, Redmond, WA, USA) was utilized for data management. Differences between the scabies group and the non-scabies control group in terms of the descriptive data, including age, income, geography, level of urbanization, and comorbidities, were analyzed using the chi-square test, while estimation of the effects of various risk factors on the hazard ratios (HRs) (with 95\% CIs) was accomplished using Cox proportional hazards regression models. These models were all adjusted for the aforementioned covariates (i.e., gender, age, income, geography, urbanization, and comorbidities), and statistical significance was determined according to a two-sided $p<0.05$.

\section{Results}

A total of 33,137 patients were enrolled in the present study, with the scabies group consisting of 6628 individuals from the NHIRD diagnosed with a scabies infection from January 2001 through December 2006. This group was compared with 26,509 control patients without scabies at a 1:4 ratio (Figure 1). There was no significant gender difference in the rate of scabies infection with younger age groups accounting for somewhat higher percentages than older age groups (Table 1). The largest percentages of the scabies patients were residents of northern Taiwan and areas of relatively high urbanization. Diabetes mellitus, hyperlipidemia, and hypertension were the most commonly occurring comorbidities. Relatedly, the scabies patients had a higher prevalence of all the comorbidities than did the participants if they were not patients in the control group.

Table 1. Age group, gender, and comorbidity distributions of the scabies group and control group subjects.

\begin{tabular}{cccc}
\hline \multirow{2}{*}{ Variable } & \multicolumn{3}{c}{ Number of (\%) Individuals } \\
\cline { 2 - 4 } & $\begin{array}{c}\text { With Scabies } \\
n=6628\end{array}$ & $\begin{array}{c}\text { Without Scabies } \\
\boldsymbol{n}=\mathbf{2 6 , 5 0 9}\end{array}$ & $\boldsymbol{p}$-Value \\
\hline Gender & & & 0.998 \\
\hline Female & $3196(48.2 \%)$ & $12,783(48.2 \%)$ & \\
Male & $3432(51.8 \%)$ & $13,726(51.8 \%)$ & 1 \\
\hline Age_Group & & & \\
\hline $20-29$ & $1797(27.1 \%)$ & $7188(27.1 \%)$ & \\
$30-39$ & $1227(18.5 \%)$ & $4908(18.5 \%)$ & \\
$40-49$ & $1236(18.6 \%)$ & $4944(18.7 \%)$ & \\
$50-59$ & $869(13.1 \%)$ & $3476(13.1 \%)$ & \\
$60-69$ & $552(8.3 \%)$ & $2208(8.3 \%)$ & \\
$\geq 70$ & $947(14.3 \%)$ & $3785(14.3 \%)$ & \\
\hline
\end{tabular}


Table 1. Cont.

\begin{tabular}{|c|c|c|c|}
\hline \multirow{2}{*}{ Variable } & \multicolumn{3}{|c|}{ Number of (\%) Individuals } \\
\hline & $\begin{array}{c}\text { With Scabies } \\
n=6628\end{array}$ & $\begin{array}{c}\text { Without Scabies } \\
n=26,509\end{array}$ & $p$-Value \\
\hline Income_Group & & & 0.001 \\
\hline$<20,000$ & $5039(76 \%)$ & $19,697(74.3 \%)$ & \\
\hline $20,000-39,999$ & $1027(15.5 \%)$ & $4287(16.2 \%)$ & \\
\hline $40,000-59,999$ & $433(6.5 \%)$ & $1817(6.9 \%)$ & \\
\hline$\geq 60,000$ & $129(1.9 \%)$ & $708(2.7 \%)$ & \\
\hline Geography & & & $<0.001$ \\
\hline North & $3053(46.1 \%)$ & $13,893(52.4 \%)$ & \\
\hline Central & $1260(19 \%)$ & $4598(17.3 \%)$ & \\
\hline South & $1993(30.1 \%)$ & $7308(27.6 \%)$ & \\
\hline Other (East+ Penghu) & $322(4.9 \%)$ & $710(2.7 \%)$ & \\
\hline Urbanization & & & $<0.001$ \\
\hline 1 (highest) & $1564(23.6 \%)$ & $8017(30.2 \%)$ & \\
\hline 2 & $2051(30.9 \%)$ & $7929(29.9 \%)$ & \\
\hline 3 & $1144(17.3 \%)$ & $4870(18.4 \%)$ & \\
\hline 4 & $1051(15.9 \%)$ & $3440(13 \%)$ & \\
\hline 5 & $144(2.2 \%)$ & $466(1.8 \%)$ & \\
\hline 6 & $362(5.5 \%)$ & $947(3.6 \%)$ & \\
\hline 7 (lowest) & $312(4.7 \%)$ & $840(3.2 \%)$ & \\
\hline \multicolumn{4}{|l|}{ Comorbidity } \\
\hline $\mathrm{DM}$ & $1372(20.7 \%)$ & $3499(13.2 \%)$ & $<0.001$ \\
\hline Hypertension & $2274(34.3 \%)$ & $6540(24.7 \%)$ & $<0.001$ \\
\hline CHD & $1239(18.7 \%)$ & $3211(12.1 \%)$ & $<0.001$ \\
\hline Hyperlipidemia & $1645(24.8 \%)$ & $5261(19.8 \%)$ & $<0.001$ \\
\hline CKD & $464(7 \%)$ & $935(3.5 \%)$ & $<0.001$ \\
\hline Atrial_fibrillation & $176(2.7 \%)$ & $375(1.4 \%)$ & $<0.001$ \\
\hline
\end{tabular}

DM, Diabetes mellitus. CHD, coronary heart disease. CKD, chronic kidney disease.

During the seven-year follow-up period, 2892 of the total of 33,137 patients enrolled in the study $(8.7 \%)$ were newly diagnosed with a stroke, including 83 from the scabies group and 2059 from the control group, accounting for $12.6 \%$ and $7.8 \%$, respectively, of the individuals in each group (Table 2).

Table 2. Cox regression analysis results regarding the degree to which a past scabies infection is predictive of subsequent stroke versus no such past infection.

\begin{tabular}{ccc}
\hline \multirow{2}{*}{ Variable } & \multicolumn{2}{c}{ Number of (\%) Individuals } \\
\cline { 2 - 3 } & With Scabies & Without Scabies \\
$n=\mathbf{6 6 2 8}$ & $n=\mathbf{2 6 , 5 0 9}$ \\
\hline With stroke & $833(12.6)$ & $2059(7.8)$ \\
Without stroke & $5795(87.4)$ & $24,450(92.2)$ \\
Crude HR & $1.67(1.54-1.81) \ddagger$ & - \\
\hline Co.001 for comparison between patients in the two groups. HR, hazard ratio.
\end{tabular}

The two groups were thus significantly different in terms of their incidences of stroke, with the scabies patients exhibiting a substantially higher risk of subsequent stroke with a crude HR $=1.67$ (95\% CI: 1.54 to 1.81). A Cox regression risk analysis was conducted and indicated an adjusted HR of 1.32 (95\% CI: 1.21 to 1.43) for the scabies patients (Table 3). Compared with younger patients, elderly patients exhibited a significantly higher risk of stroke $(a H R=7.99$ for patients aged $>70)$. Patients with 
hypertension, coronary heart disease, and atrial fibrillation were also at significantly higher risks of stroke $(\mathrm{aHR}=3.19,1.63$, and 1.61, respectively $)$.

Table 3. Cox regression analysis results regarding the degree to which independent factors are predictive of stroke.

\begin{tabular}{|c|c|c|}
\hline \multirow{2}{*}{ Variable } & Crude & Adjusted \\
\hline & HR $(95 \%$ CI) & $\mathrm{HR} *(95 \% \mathrm{CI})$ \\
\hline Scabies & $1.67(1.54-1.81) \ddagger$ & $1.32(1.21-1.43) \ddagger$ \\
\hline \multicolumn{3}{|l|}{ Gender } \\
\hline Female & 1 & - \\
\hline Male & $1.06(0.99-1.14)$ & - \\
\hline \multicolumn{3}{|l|}{ Age_Group } \\
\hline $20-29$ & 1 & 1 \\
\hline $30-39$ & $2.01(1.58-2.57) \ddagger$ & $1.69(1.32-2.16) \ddagger$ \\
\hline $40-49$ & $4.4(3.56-5.46) \ddagger$ & $2.63(2.11-3.28) \ddagger$ \\
\hline $50-59$ & $9.51(7.74-11.68) \ddagger$ & $3.74(3.01-4.65) \ddagger$ \\
\hline $60-69$ & $18.49(15.1-22.64) \ddagger$ & $5.53(4.46-6.87) \ddagger$ \\
\hline$\geq 70$ & $24.32(20.05-29.52) \ddagger$ & $7.99(6.49-9.83) \ddagger$ \\
\hline \multicolumn{3}{|l|}{ Income_Group } \\
\hline$<20,000$ & 1 & 1 \\
\hline $20,000-39,999$ & $0.54(0.47-0.6) \ddagger$ & $1.02(0.9-1.17)$ \\
\hline $40,000-59,999$ & $0.44(0.36-0.54) \ddagger$ & $0.77(0.62-0.94)^{+}$ \\
\hline$\geq 60,000$ & $0.58(0.43-0.76) \ddagger$ & $0.72(0.54-0.96)^{+}$ \\
\hline \multicolumn{3}{|l|}{ Geography } \\
\hline North & 1 & 1 \\
\hline Central & $1.13(1.02-1.25) \ddagger$ & $0.94(0.84-1.05)$ \\
\hline South & $1.23(1.13-1.34) \ddagger$ & $0.96(0.87-1.05)$ \\
\hline Other (East+ Penghu) & $1.73(1.45-2.06) \ddagger$ & $1.03(0.86-1.25)$ \\
\hline \multicolumn{3}{|l|}{ Urbanization } \\
\hline 1 (highest) & 1 & 1 \\
\hline 2 & $1.07(0.97-1.19)$ & $1.04(0.94-1.16)$ \\
\hline 3 & $1.2(1.07-1.35)^{\dagger}$ & $1.14(1.01-1.28)^{\dagger}$ \\
\hline 4 & $1.61(1.44-1.81) \ddagger$ & $1.15(1.01-1.29)^{\dagger}$ \\
\hline 5 & $2.31(1.86-2.86) \ddagger$ & $1.18(0.94-1.47)$ \\
\hline 6 & $1.84(1.55-2.17) \ddagger$ & $1.07(0.9-1.29)$ \\
\hline 7 (lowest) & $1.85(1.55-2.21) \ddagger$ & $1.13(0.94-1.37)$ \\
\hline \multicolumn{3}{|l|}{ Comorbidity } \\
\hline DM & $4.44(4.12-4.78) \ddagger$ & $1.36(1.25-1.47) \ddagger$ \\
\hline Hypertension & $9.4(8.64-10.23) \ddagger$ & $3.19(2.88-3.54) \ddagger$ \\
\hline CHD & $6.25(5.81-6.73) \ddagger$ & $1.63(1.5-1.77) \ddagger$ \\
\hline Hyperlipidemia & $3.09(2.87-3.32) \ddagger$ & $1.16(1.07-1.26) \ddagger$ \\
\hline CKD & $4.89(4.42-5.41) \ddagger$ & $1.25(1.13-1.39) \ddagger$ \\
\hline Atrial_fibrillation & $7.36(6.47-8.38) \ddagger$ & $1.61(1.4-1.84) \ddagger$ \\
\hline
\end{tabular}

* Each variable was adjusted for every other variable listed whose crude HR was significant $(p<0.05) .{ }^{\dagger} p<0.05$ for comparison between patients with two groups. $\ddagger p<0.001$ for comparison between patients with two groups.

\section{Discussion}

This study is, to our knowledge, the first population-based national study to investigate the relationship between scabies and stroke. The 6628 patients in the scabies group exhibited an increased risk of subsequent stroke compared to the 26,509 patients in the control group, with an adjusted HR of 1.32 for the scabies group. This finding suggested that the early and aggressive treatment of scabies might serve to lower the risk of subsequent stroke in scabies patients.

Atherosclerosis constitutes an inflammatory process that is mediated by the immune system, with vessel atherosclerosis being interacted with and accelerated by the systemic inflammation that occurs in the pathogenesis of autoimmune diseases [16,17]. Similarly, immune-mediated host inflammation 
after infestation by Sarcoptes scabiei is also found in scabies [6,15-18], along with elevated levels of interleukin (IL)-4 and IL-6 [6,14,18], the latter of which is an upstream inflammatory cytokine that has been found to play a key role in both atherosclerosis and coronary heart disease [19,20]. Moreover, fatty lesion development in mice has been found to be enhanced by IL-6, which indicates that it is a proatherogenic cytokine [21]. Studies of animal models have further indicated that IL-4 might also play a role in atherosclerosis via the induction of inflammatory responses [22,23], while atherosclerosis itself is a leading pathogenic mechanism of stroke. One of the key pathologic processes of early atherosclerosis, meanwhile, is endothelial dysfunction, which has been found to be associated with cytokine regulation [20,24]. Besides, some studies have pointed out that Pelvic Inflammation Disease (PID) is the same as rhinosinusitis, which causes atherosclerosis to produce stroke by inflammatory reaction [11,12]. Finally, according to the results of the present study, traditional cardiovascular risk factors are more prevalent in patients with scabies.

Elderly patients, who tend to have atherosclerosis, and male patients exhibited relatively high risks of subsequent stroke in this study, especially patients older than 70 years of age. This finding was not surprising, as old age is already well-known to be a major risk factor for stroke [25], with the incidence of stroke more than doubling in both men and women for every 10 years of age above 55 years old [26,27]. As noted, the results of this study were consistent with those earlier findings insofar as the patients who were older than 70 years of age had a much higher risk of stroke ( $\mathrm{aHR}=7.99$, $95 \% \mathrm{CI}=6.49-9.83$ ) than the young patients. On the other hand, while different areas have widely differing incidences of scabies, scabies has already been reported to be more common in children and adolescents than in adults in general [2,3]. The current study of adults was consistent with that insofar as scabies infections were found to be more common in young adults than in older adults, with scabies and stroke having markedly different ages of peak incidence.

Higher incidences of diabetes mellitus, hypertension, coronary heart disease, hyperlipidemia, and atrial fibrillation, all of which were found to be risk factors for stroke, were found in the scabies group than in the control group. Moreover, increased stroke risk was still found for the scabies patients even after adjustment with Cox regression analysis.

Finally, it is also worth noting that medications used to treat scabies, such as topical permethrin, lindane, benzyl benzoate, and oral ivermectin, may have stimulatory effects on the central nervous system, but no association between stroke and the use of these drugs has yet been reported.

\section{Limitations}

The present study has several limitations. First, while the NHIRD covers approximately $99 \%$ of Taiwan's 23 million residents, meaning that the data analyzed for this study is representative of the entire national population, the study's cross-sectional design nonetheless means that the causal relationship, if any, between scabies and stroke cannot be directly determined. Second, the NHIRD does not include detailed laboratory test clinical data regarding patients' functional neurologic status, nor does it include details regarding the size and location of cerebral infarcts or hemorrhages. Third, the NHIRD also lacks any data regarding individual behaviors and characteristics, such as smoking, alcohol consumption, and body mass index, that are already known to be major risk factors for stroke.

\section{Conclusions}

In summary, this population-based nationwide study of Taiwan provided evidence, demonstrating a possible connection between scabies and stroke. Specifically, an elevated risk of stroke was noted in patients with scabies, who had an adjusted HR of 1.32. Awareness of this finding may help encourage clinicians to remain alert to any signs or symptoms of stroke in patients with previous scabies infection.

Author Contributions: M.-H.W., H.P. and Y.-C.L. wrote the proposal and prepared the manuscript. C.-Y.L. contributed to the conception and designed the manuscript. M.-H.W. and Y.-C.L. conducted data analysis. H.P. and Y.-C.L. collected the data and helped to prepare the manuscript. M.-H.W., C.-Y.L. and Y.-C.L prepared the 
manuscript and did data analysis. H.P. and Y.-C.L. revised the manuscript and did data analysis. All authors read and approved the final manuscript.

Funding: This study was supported in parts by grants AFTYGH-10850 from Taoyuan Armed Forces General Hospital. The funders had no role in study design, data collection and analysis, decision to publish, or preparation of the manuscript.

Acknowledgments: The implications and conclusions do not represent the opinions of the Bureau of National Health Insurance, the Department of Health, or the National Health Research Institute.

Conflicts of Interest: The authors declare no conflict of interest.

\section{Abbreviations}

$\begin{array}{ll}\text { aHR } & \begin{array}{l}\text { Adjusted hazard ratio } \\ \text { CI }\end{array} \\ \text { HR } & \text { Hazfidence interval } \\ \text { ICD-9-CM } & \begin{array}{l}\text { The International Classification of Diseases, Ninth } \\ \text { Revision, Clinical Modification }\end{array} \\ \text { IL } & \text { Interleukin } \\ \text { NHIRD } & \text { National Health Insurance Research Database } \\ \text { LHID2000 } & \text { Longitudinal Health Insurance Database 2000 } \\ \text { Th17 } & \text { T helper 17 cells } \\ \text { PID } & \text { Pelvic Inflammation Disease }\end{array}$

\section{References}

1. Chosidow, O. Scabies. N. Engl. J. Med. 2006, 354, 1718-1727. [CrossRef]

2. Romani, L.; Steer, A.C.; Whitfeld, M.J.; Kaldor, J.M. Prevalence of scabies and impetigo worldwide: A systematic review. Lancet Infect. Dis. 2015, 15, 960-967. [CrossRef]

3. Romani, L.; Koroivueta, J.; Steer, A.C.; Kama, M.; Kaldor, J.M.; Wand, H.; Hamid, M.; Whitfeld, M.J. Scabies and impetigo prevalence and risk factors in Fiji: A national survey. PLoS Negl. Trop. Dis. 2015, 9, e0003452. [CrossRef]

4. Turkmen, K.; Erdur, M.F.; Kucuk, A. Risk factors that can affect the progression of chronic kidney disease in patients with poststreptecoccal glomerulonephritis history. Kidney Int. 2013, 83, 762. [CrossRef]

5. Chung, S.D.; Wang, K.H.; Huang, C.C.; Lin, H.C. Scabies increased the risk of chronic kidney disease: A 5-year follow-up study. J. Eur. Acad. Dermatol. Venereol. 2014, 28, 286-292. [CrossRef]

6. Walton, S.F.; Oprescu, F.I. Immunology of scabies and translational outcomes: Identifying the missing links. Curr. Opin. Infect. Dis. 2013, 26, 116-122. [CrossRef]

7. Donnan, G.A.; Fisher, M.; Macleod, M.; Davis, S.M. Stroke. Lancet 2008, 371, 1612-1623. [CrossRef]

8. Ra, G.S.; Yoo, J.C.; Kang, C.J.; Kim, Y.S. Microfabricated in-channel structured polydimethylsiloxane microfluidic system for a lab-on-a-chip. J. Nanosci. Nanotechnol. 2008, 8, 4588-4592. [CrossRef]

9. Jakovljevic, D.; Sarti, C.; Sivenius, J.; Torppa, J.; Mähönen, M.; Immonen-Räihä, P.; Kaarsalo, E.; Alhainen, K.; Kuulasmaa, K.; Tuomilehto, J.; et al. Socioeconomic status and ischemic stroke: The FINMONICA Stroke Register. Stroke 2001, 32, 1492-1498. [CrossRef]

10. Lin, H.C.; Lin, Y.J.; Liu, T.C.; Chen, C.S.; Chiu, W.T. Urbanization and stroke prevalence in Taiwan: Analysis of a nationwide survey. J. Urban Health 2007, 84, 604-614. [CrossRef]

11. Chen, P.C.; Tseng, T.C.; Hsieh, J.Y.; Lin, H.W. Association between stroke and patients with pelvic inflammatory disease: A nationwide population-based study in Taiwan. Stroke 2011, 42, 2074-2076. [CrossRef] [PubMed]

12. Wu, C.W.; Chao, P.Z.; Hao, W.R.; Liou, T.H.; Lin, H.W. Risk of stroke among patients with rhinosinusitis: A population-based study in Taiwan. Am. J. Rhinol. Allergy 2012, 26, 278-282. [CrossRef] [PubMed]

13. Abd El-Aal, A.A.; Hassan, M.A.; Gawdat, H.I.; Ali, M.A.; Barakat, M. Immunomodulatory impression of anti and pro-inflammatory cytokines in relation to humoral immunity in human scabies. Int. J. Immunopathol. Pharmacol. 2016, 29, 188-194. [CrossRef] [PubMed]

14. Liu, X.; Walton, S.F.; Murray, H.C.; King, M.; Kelly, A.; Holt, D.C.; Currie, B.J.; McCarthy, J.S.; Mounsey, K.E. Crusted scabies is associated with increased IL-17 secretion by skin T cells. Parasite Immunol. 2014, 36, 594-604. [CrossRef] [PubMed] 
15. Mounsey, K.E.; Murray, H.C.; Bielefeldt-Ohmann, H.; Pasay, C.; Holt, D.C.; Currie, B.J.; Walton, S.F.; McCarthy, J.S. Prospective study in a porcine model of Sarcoptes scabiei indicates the association of Th2 and Th17 pathways with the clinical severity of scabies. PLoS Negl. Trop. Dis. 2015, 9, e0003498. [CrossRef]

16. Ross, R. Atherosclerosis-An inflammatory disease. N. Engl. J. Med. 1999, 340, 115-126. [CrossRef]

17. Abou-Raya, A.; Abou-Raya, S. Inflammation: A pivotal link between autoimmune diseases and atherosclerosis. Autoimmun. Rev. 2006, 5, 331-337. [CrossRef] [PubMed]

18. Mullins, J.S.; Arlian, L.G.; Morgan, M.S. Extracts of Sarcoptes scabiei De Geer downmodulate secretion of IL-8 by skin keratinocytes and fibroblasts and of GM-CSF by fibroblasts in the presence of proinflammatory cytokines. J. Med. Entomol. 2009, 46, 845-851. [CrossRef]

19. Hartman, J.; Frishman, W.H. Inflammation and atherosclerosis: A review of the role of interleukin-6 in the development of atherosclerosis and the potential for targeted drug therapy. Cardiol. Rev. 2014, 22, 147-151. [CrossRef]

20. Tedgui, A.; Mallat, Z. Cytokines in atherosclerosis: Pathogenic and regulatory pathways. Physiol. Rev. 2006, 86, 515-581. [CrossRef]

21. Huber, S.A.; Sakkinen, P.; Conze, D.; Hardin, N.; Tracy, R. Interleukin-6 exacerbates early atherosclerosis in mice. Arterioscler. Thromb. Vasc. Biol. 1999, 19, 2364-2367. [CrossRef] [PubMed]

22. King, V.L.; Szilvassy, S.J.; Daugherty, A. Interleukin-4 deficiency decreases atherosclerotic lesion formation in a site-specific manner in female LDL receptor-/- mice. Arterioscler. Thromb. Vasc. Biol. 2002, 22, 456-461. [CrossRef] [PubMed]

23. Davenport, P.; Tipping, P.G. The role of interleukin-4 and interleukin-12 in the progression of atherosclerosis in apolipoprotein E-deficient mice. Am. J. Pathol. 2003, 163, 1117-1125. [CrossRef]

24. Mantovani, A.; Bussolino, F.; Dejana, E. Cytokine regulation of endothelial cell function. FASEB J. 1992, 6, 2591-2599. [CrossRef] [PubMed]

25. Boysen, G.; Nyboe, J.; Appleyard, M.; Sørensen, P.S.; Boas, J.; Somnier, F.; Jensen, G.; Schnohr, P. Stroke incidence and risk factors for stroke in Copenhagen, Denmark. Stroke 1988, 19, 1345-1353. [CrossRef] [PubMed]

26. Brown, R.D.; Whisnant, J.P.; Sicks, R.D.; O'Fallon, W.M.; Wiebers, D.O. Stroke incidence, prevalence, and survival: Secular trends in Rochester, Minnesota, through 1989. Stroke 1996, 27, 373-380.

27. Wolf, P.A.; D'Agostino, R.B.; O’Neal, M.A.; Sytkowski, P.; Kase, C.S.; Belanger, A.J.; Kannel, W.B. Secular trends in stroke incidence and mortality: The Framingham Study. Stroke 1992, 23, 1551-1555. [CrossRef] [PubMed] 